\title{
樆 \\ First report of Pepo aphid-borne yellows virus in cucurbits in Tanzania and Mayotte
}

\author{
C. Desbiez ${ }^{1}$, P. Millot ${ }^{1}$, C. Wipf-Scheibel ${ }^{1}$, D. Blancard ${ }^{2}$, T. Chesneau $^{3}$ and H. Lecoq ${ }^{1}$ \\ ${ }^{1}$ INRA, UR0407 Pathologie Végétale, F-84140 Montfavet, France; ${ }^{2}$ INRA, UMR SAVE, ISVV, F-33883 Villenave d'Ornon, \\ France; ${ }^{3}$ Lycée Agricole de Mayotte BP 02, 97670 Coconi, Mayotte
}

*E-mail: cecile.desbiez@avignon.inra.fr

Received: 19 Apr 2016. Published: 04 May 2016. Keywords: melon, Polerovirus, watermelon

Despite their effects on crop yield, poleroviruses are often overlooked because their symptoms, yellowing in mature leaves, may be inconspicuous or confused with nutrient deficiency. In cucurbits, the only polerovirus known for a long time was Cucurbit aphid-borne yellows virus (CABYV; Lecoq et al., 1992). However, molecular studies have revealed that at least six different species infect this plant family: CABYV which is present worldwide, four species (Cucumber aphid-borne yellows - Hainan virus, Luffa aphid-borne yellows virus, Melon aphid-borne yellows virus and Suakwa aphid-borne yellows virus) found only in Asia, and Pepo aphidborne yellows virus (PABYV) first observed in 2008 in Mali (Knierim et al., 2014), and more recently in South Africa (Ibaba et al., 2015), Côte d'Ivoire (Kone et al., 2015) and Greece (Lotos et al., 2016). Sequence data indicate that PABYV was also present in Syria in 2009 (GenBank Accession No. KC960436).

Two samples of melon showing yellowing symptoms (Fig. 1) were collected in December 2012 in the Kawéni locality on Mayotte in the Mozambique Channel, and stored as dried material. Two samples of watermelon showing yellowing symptoms were also collected in February 2013 near Arusha, Tanzania. The four samples were negative in DAS-ELISA with antisera raised against Cucumber mosaic virus, Cucumber vein yellowing virus, Moroccan watermelon mosaic virus, Papaya ringspot virus, Watermelon mosaic virus and Zucchini yellow mosaic virus, however the Tanzanian samples reacted positively with a CABYV antiserum. Total RNA was extracted from infected tissues using the TRI-reagent, and RT-PCR was performed with polerovirus primers Pol-G-F and Pol-G-R (Knierim et al., 2014). A $1.1 \mathrm{~kb}$ fragment was obtained from all samples, and sent to Genoscreen (Lille, France) for direct sequencing. The sequences obtained, encompassing part of the polerovirus RNA-dependent RNA polymerase, intergenic region, coat protein and movement protein, shared a close relationship with PABYV isolates from different origins (Fig. 2), with more than $92 \%$ nucleotide identity with all PABYV sequences available to date.

To our knowledge, this is the first report of PABYV in East Africa and in Mayotte. The two isolates from Mayotte (KT943910-KT943911) generated amplicons whose sequences shared $99.8 \%$ identity, whereas the sequences

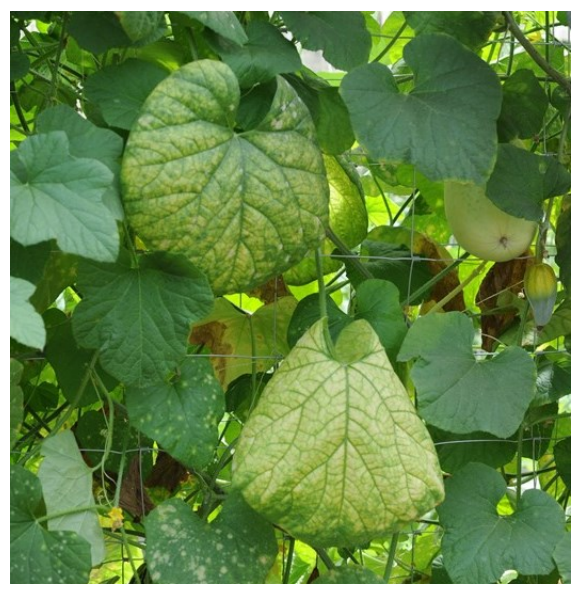

Figure 1

To cite this report: Desbiez C, Millot P, Wipf-Scheibel C, Blancard D, Chesnea virus in cucurbits in C 2016 The Authors from Tanzanian isolates (KT943912-KT943913) were 99\% identical. The Tanzanian isolates shared $94 \%$ identity with the Mayotte isolates. There was no evidence for recombination following examination of the amplicon sequences for all isolates. The molecular diversity of PABYV appears similar to that of the ubiquitous CABYV in this part of the genome, suggesting that the widespread distribution of PABYV in Africa is not the result of a recent emergence from a narrow genetic base. The virus may have been present for a long time but has probably been overlooked due to its moderate and non-specific yellowing symptoms and the lack of specific diagnostic tools. These results confirm the broad geographic spread of PABYV in Africa, and show that this virus, and other mosaic- and yellowsinducing cucurbit viruses, need to be considered in breeding programmes and during crop protection activities.

\section{References}

Ibaba JD, Laing MD, Gubba A, 2015. Incidence and phylogeny of viruses infecting cucurbit crops in KwaZulu-Natal, Republic of South Africa. Crop Protection 75, 46-54. http://dx.doi.org/10.1016/j.cropro.2015.04.019

Knierim D, Tsai WS, Maiss E, Kenyon L, 2014. Molecular diversity of poleroviruses infecting cucurbit crops in four countries reveals the presence of members of six distinct species. Archives of Virology 159, 1459-1465. http://dx.doi.org/10.1007/s00705-013-1939-5

Koné N, Coulibaly A, Koita O, Koné D, Bediako EA, Knierim D, Menzel W, Winter S, 2015. First report of Pepo aphid-borne yellows virus on zucchini in Cote d'Ivoire. New Disease Reports 31, 27. http://dx.doi.org/10.5197/j.2044-0588.2015.031.027

Lecoq H, Bourdin D, Wipf-Scheibel C, Bon M, Lot H, Lemaire O, Herrbach E, 1992. A new yellowing disease of cucurbits caused by a luteovirus, cucurbit aphid-borne yellows virus. Plant Pathology 41, 749-761. http://dx.doi.org/10.1111/j.1365-3059.1992.tb02559.x

Lotos L, Maliogka VI, Katis NI, 2016. New poleroviruses associated with yellowing symptoms in different vegetable crops in Greece. Archives of Virology 161, 431-436. http://dx.doi.org/10.1007/s00705-015-2662-1

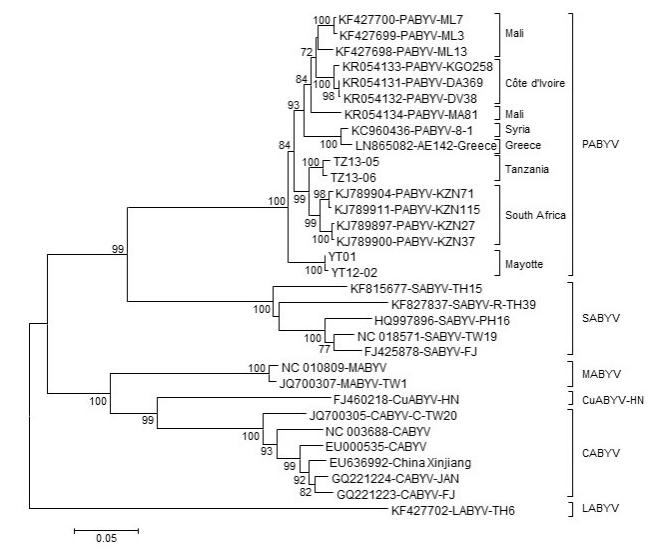

Figure 2 